\title{
Problems with Object Permanence: Rethinking Traditional Beliefs Associated with Poor Theory of Mind in Autism
}

\author{
Wenn B. Lawson ${ }^{1, *}$ and Brynn A. Dombroski ${ }^{2}$ \\ ${ }^{1}$ ACRC, The University of Queensland, C/O PO Box 5033, Warrnambool, Vic. 3280, Australia \\ ${ }^{2}$ University of Louisville, College of Education and Human Development, 1905 South 1st Street, Louisville, \\ KY, 40292, USA
}

\begin{abstract}
Poor Theory of Mind (ToM) (or difficulties imputing mental states to self and others) [1], (See also [2-5]) is often blamed for certain responses and behaviour in autism. However, the Theory of Mind Task Battery requires an understanding of language, the use of cognitive skills, as well as the child's motivation and attention to complete. All of these factors are either weak or under-developed in individuals with autism suggesting that this is not the best means to measure one's understanding that other people have their own thoughts, plans, beliefs, or point of view. Behaviours like strong defiance, insistence on sameness, fear associated with sudden change and severe anxiety may be related to difficulties seeing beyond the 'now' [6]. This paper suggests that some of the stress and anxiety in the autism population may actually be due to delayed object permanence (OP) (knowing something may still exist even if it is out of sight), which can appear as poor ToM. This delay in establishing OP is governed by single focused attention. For more information on this concept see: Lawson, W. (2011) The passionate mind, JKP:London. Although ToM and OP are defined differently, this paper aims to show the relationship between them and how one concept can influence the other using examples in everyday life to illustrate how poor OP is associated with single focused attention, which detracts from the bigger picture.
\end{abstract}

Keywords: Autism, Object Permanence, Theory of Mind, Single Attention, Interest.

\section{INTRODUCTION}

Many individuals diagnosed with an autism spectrum disorder (ASD) (the authors prefer individuals on the autism spectrum) find it difficult to maintain eye contact, identify emotions of self and others, and are often limited in their ability to generalise concepts without exploring the variability and application of certain scripts $[7,8]$. This failure to generalize concepts has frequently been associated with poor theory of mind (ToM). The ability to comprehend object permanence (OP) involves attending to multiple stimuli in order to appreciate concepts such as here, now, gone, later, hidden, and so on [6]. The author's postulate poor ToM is influenced by a poor understanding of OP and, at times is a separate issue all together. For example, it might be assumed that if a child notices something is moved from its usual place (e.g. a book or a toy) that child has an understanding of OP because they know the object was there and now it is not. However, poor understanding of OP may be contributing to insistence upon sameness and routine due to non-comprehension of the continued existence of the object, person, time or event. It is not simply its removal that causes the discomfort, it may be the belief it is never returning. Therefore, trying to reason with the child amongst responses of fear, anger, anxiety and

*Address correspondence to this author at the ACRC, Long Pocket Campus, The University of Queensland, PO Box 5033, Warrnambool, Vic. 3280, Australia; E-mail: wenbe2@outlook.com grief, will not placate the situation. OP needs to be established in order to support the individual through instances of 'change' which of course are related to the ToM and the ability to shift from one's own beliefs to that of others.

The original Sally-Anne test used by Baron-Cohen, et al. [4] is a test of false belief. It is also referred to as the classic test for 'mind reading', and is used to assess ToM in children. It is expected that children who possess a cognitively intact ToM will be able to pass this test by the time they are 5 years old. Additionally, the Sally-Anne test was intended to demonstrate how many children on the autism spectrum fail to appreciate beliefs that differ from their own.

In the Sally-Anne test, the experimenter introduces the child to two dolls, one called Sally and one called Anne. The experimenter uses the dolls to illustrate the following story: Sally has a basket and Anne has a box. Sally has a marble that she puts inside her basket to keep it safe while she goes outside to play. While Sally is away, Anne moves Sally's marble from Sally's basket into her box. The child is then asked, "where is the marble now?" "where did Sally put the marble in the beginning?" and "when Sally comes back from playing, where will she look for her marble?" By age 5, all children should be able to answer that the marble is now in Anne's box and that in the beginning, Sally put the marble inside her basket. As for the third question, often, but not always, children on the autism spectrum 
say, "Sally will look in the box where the marble is." While Sally will certainly find the marble inside Anne's box, this does not accurately answer the question and is therefore incorrect.

According to the story, Sally had gone outside to play, therefore, she did not see Anne move the marble, nor would she have any knowledge that her marble had been moved. The incorrect response to, "where will Sally look for her marble?" has traditionally been interpreted as the child failing to have a theory of mind (ToM) because he/she cannot attribute a false belief to this scenario' (that belief being "false" because it differs from his/her own). This has been taken even further to suggest that children on the autism spectrum lack empathy because they fail to see another person's point of view. However, this thinking is completely false. Individuals with autism do not lack empathy. Instead, many individuals with autism lack the ability to process subtle cues related to another person's emotions, which makes it difficult for them to respond appropriately. Teaching emotions and pairing facial expressions with emotional labels is extremely helpful in teaching how to read these cues. The use of social stories and videos are two other ways to teach individuals with autism how to recognize, respond, and 'connect' with someone else's emotions.

In ASD, attending to several events simultaneously is difficult to manage due to being singly focussed and/or overloaded by sensory stimuli [7, 9-13]. ASD individuals are often hyper- or hyposensitive to light, sound, smell, taste, or texture. When processing one's surrounding environment, the ASD mind must simultaneously filter sensory stimulation while sifting through scripting information in order to determine which script(s) to apply to which stimuli $[6,14]$. Additionally, the ASD mind must first be attending to the situation in order to process both the surrounding environment and analyse which script is most appropriate.

ASD individuals may seem to grasp OP in some cases, but not in others. This actually has more to do with a lack of information impeding their ability to generalise concepts. For example, in regards to hidden objects, previously illustrated by Lawson and Dombroski [8], two girls with ASD might have developed an OP script for what belongs inside their lunch bags, but not have an OP script for where their mother is if she is not within their sight. After the girls have each packed a sandwich, snack, and drink bottle inside their lunch bag and sealed it, they know that even though they cannot see their sandwich, snack, and drink bottle, those items are packed safely inside their lunch bags. These same girls may be playing inside while their mother is in view cleaning the kitchen. However, if their mother leaves the room, but not the house, these girls may panic and exhibit separation anxiety as they jump to the irrational conclusion that because Mummy is no longer within their view, Mummy must have disappeared and may not be coming back. How is it they know one concept, but not the other?

Lawson and Dombroski [8] posit that this can be viewed as a lack of "big picture" thinking which requires a full range of cognitive and sensorimotor skills to work synchronously within the brain to determine, "where am I?" and "where is it/they/them?" especially in regards to object permanence and generalization; this is not a ToM issue.

In the past, researchers have failed to appreciate the relevance of OP in ASD and instead sided with the idea that social difficulties observed in ASD are due to only a lack of ToM, poor executive functioning or/and impaired central coherence [15]. But, what if the accepted understanding of TOM and suggested connections to empathy were not the same thing? What if children with ASD fail to pass ToM tests due to a lack, or faulty processing of OP? The purpose of this paper is to provide an alternative perspective regarding social communication difficulties in autism and to encourage further discussion on rethinking ideas connecting ToM issues and ASD.

If professionals and caregivers of individuals with ASD negate the fact that some behaviours may actually stem from a lack of OP, they may be failing to provide appropriate education, resources, and interventions. For example, to look at and listen to someone, while walking and eating lunch all at the same time, requires multi-tasking attention. In ASD, to simply focus on just one of these tasks at a time, for instance, looking at the person who is speaking, takes all of an ASD individual's attention [8, 14, 16, 17].

For ASD individuals, engaging in conversation and rehearsing each step of verbal instruction requires a great deal of mental effort. As one might expect, thinking ahead (outside of interest and connection) is not typical behaviour in individuals with ASD. This is one of the main reasons why ASD individuals have "meltdowns" when something goes awry. However, as with neuro-typical individuals, the more experience someone with ASD has dealing with unforeseen 
circumstances, the better able he/she might be at processing and navigating the situation. For instance, when taking public transportation, the bus may be late, the bus may incur a flat, the regular bus might be at the mechanic's and a substitute bus might be taking over the route, or there may be a detour, and so on. Schemas and forward thinking are essential in determining how to respond to each circumstance. Forward thinking is also necessary to be able to recognize and rationalize object permanence. For instance, when answering questions to the Sally-Anne test, one must use forward thinking to process that Sally did not know that Anne had moved the marble, and that Sally would not instinctively know to look inside Anne's box for it. Instead, Sally would need to first learn that her marble was missing, and then problem solve to figure out where it might be. However, individuals with autism process information so literally that they would not consider a script for a missing marble because the marble is not missing; it is inside the box. It would be false to say that Sally should look inside her basket when they clearly see that the marble is inside Anne's box. In summary, ToM is about seeing and feeling things from the other person's perspective, while OP is about cognitively being able to forward think, see the bigger picture, and recognize other possibilities.

According to Lawson [14] this process of how attention is used in autism is called single attention and associated cognition in autism (SAACA). If John Doe has a brain that attends to one thing at a time, for example, seeing, then listening, then thinking, rather than attending to all information being processed at the same time, John Doe will most likely exhibit social and communication difficulties. As a way to self-filter some of the over powering stimuli, children with ASD might listen to others while avoiding looking at them; that way they can funnel all of their cognitive efforts into hearing a person speak instead of internally competing over which stimuli is more dominant, sight or sound. Unless the person is someone they know well, looking and listening at the same time is often too demanding of the brain's attention [19]. Of course, many ASD individuals perform much better at a whole range of activities when they are motivated via interest. As we know, motivation switches on GAMMA that enable the brain to build connections [20].

\section{IMPLICATIONS}

For most people, communicating through in-person conversation involves processing incidental cues observed by the speaker, including body language, tone of voice, inflection and facial expressions. However, as previously mentioned, these additional stimuli are often too much for an ASD individual to process at the same time and as a result, are often overlooked and missed entirely. Yet, these are necessary links to reading a variety of situations that enable appreciation of OP.

Body language is the term used to describe "speaking with our bodies" (e.g. one's facial expression, hand gestures, posture, stance, eye rolling, etc.). Sometimes a person may say one thing, but mean another. For example, the phrase, "Oh, great!" typically sounds like a good thing, but if the person speaking changed his/her tone of voice or inflection while saying this phrase and maybe paired it with eye rolling and a hand gesture involving moving both hands up in the air while speaking, it would indicate that in this particular case, the phrase "Oh, great!" is being used as sarcasm in response to something that is actually not a good thing. An understanding of sarcasm is paramount to a richer appreciation of ToM. It also helps to create a picture of current expectations. For example, if a neuro-typical individual and an individual with autism are both waiting for the bus, and then the neuro-typical individual states, "Oh great, the bus has gone!" It is very likely that the individual with autism may not understand that the other person is actually upset that the bus is gone. Additionally, the phrase, "the bus is gone" does not provide any information as to whether the bus is coming back. A foundational basis of OP would help the individual with autism to understand that more than one bus may come to that particular bus stop or that the same bus may come to that bus stop several times day according to a daily bus routing schedule.

Small talk: Small talk is sometimes thought of as informal, non-meaningful introductory statements that open a conversation. The following dialogue is a brief example: Person A: "Hello," Person B: "Hello," Person A: "How are you?" Person B: "I'm well, how are you?" Person A: "I'm well too. Nice weather isn't it? Do you come here often?" and so on. It requires forward thinking to be able to identify when and how to end the informal conversation.

Unfortunately, many individuals with ASD really struggle to identify these subtle and sometimes not-sosubtle cues once the informal conversation leads to a topic of interest. For example, someone with ASD may be fascinated by trains or toads, and if a train horn is 
heard or a toad hops along nearby or somehow train or toad are brought into the conversation, it is likely that the ASD individual will continue to speak in volumes about either topic, and be completely unaware of the listener's lack of interest. This may not be a ToM issue but rather one connected to the outcomes of SAACA and OP. The author's argue for poor OP because if the individual with autism finds it difficult to forward think or appreciate ending a conversation is not truly 'the end' this says more about cognitive connectivity than it does about ToM.

Metaphor: Individuals, not living with ASD, often speak in metaphor. Metaphor is the use of certain words or phrases applied to an object or action that it does not literally mean, but is used to express the intensity of the situation. For example, in the U.K., the expression, "it's bucketing down," or in the U.S.A., "It's raining cats and dogs" does not literally mean that there are lots of buckets or cats and dogs falling down from the sky. In fact, it means lots of rain is coming down, as if it were coming down in bucket loads or the size of cats and dogs. The use of metaphor in conversation requires the listener to decipher the speaker's metaphorical code. This level of cognitive processing is necessary for OP, ToM, forward thinking, and big picture thinking.

Joking or being cynical are also common ways of conversing, especially when there is tension or uncomfortable silence within a room, or when someone simply wants to elicit the response of laughter to ease the mood of the crowd. For example, if three people walk into an elevator and unexpectedly find that someone before them had pressed the button to every floor that the elevator could stop on, one of the three people might jokingly say, "Hey, it wasn't me" or "Abracadabra" just before the elevator doors open and then say to his fellow passengers, "Hey, I'm getting really good at this magic stuff." Of course, it is not magical at all, it is simply one person's attempt to ease any discomfort or frustration that can be felt amongst those inside the elevator. Again, this requires the efforts of higher level thinking to be able to discriminate between what is real, what is perceived, and what is intended by the joke. The ability to understand and respond to a joke involves both ToM and big picture thinking to access the appropriate script for responding.

Teasing: Teasing is not the same as joking. Teasing is usually directed toward a particular person and is often (but not always) done in good humour. For example, a person may have big, curly hair that stands out, so a friend might jokingly say to a small group of their friends, "Old curly top here thinks differently; don't you curly?" as he ruffles his fingers through his friend's curly hair. The person with curly hair is not offended, because he recognizes that his friend was merely teasing. For an ASD individual, reading intention requires forward thinking and a good sense of OP. If these are not well formed, an ASD person might take offense.

Masking is a way of covering up one's true feelings or "putting on a brave face." Begeer et al., [21] examined the understanding and self-reported use of rules for the expressive display of emotions in children with high functioning autism compared to neurotypically developing controls in two experiments. In experiment 1, both ASD and control children were given descriptions that explicitly provided prosocial or self-protective motives for masking the display of emotion (sparing others' feelings, or protecting oneself from aversive outcomes [21]). Both groups of children where then given hypothetical situations and asked to describe their feelings and which facial expression they would display. The results of experiment 1 showed that ASD children were able to report appropriate emotion masking displays when provided with hypothetical scenarios that included explicit prosocial or selfprotective motives for concealing emotional expressions. Begeer et al., [21] posited that these results suggest that ASD individuals are capable of recognizing the appropriate story elements and are familiar with the basic principles of emotional display rules. In experiment 2 , the researchers conducted a semi-structured interview addressing children's selfperceived ability to control their display of basic emotions including anger, fear, sadness and happiness. Researchers encouraged children to report examples of their personal experiences with emotional display rules. Results of experiment 2 showed that ASD children failed to describe situations that would elicit emotional display rules more often than controls and reported far less personal experiences for emotional display rules than controls.

Begeer and colleagues [21] suggest their study provides evidence that autistic individuals have more difficulty interpreting interpersonal functions of emotional display rules than controls. They believe that this explains why ASD children had tried to hide or mask emotions from others less often than controls. Begeer et al. [21] concluded that high functioning autistic individuals were only successful in negotiating which emotional display rule applies to which situation when adequate contextual support was provided. 
As adults, neurto-typical individuals learn to mask their emotions of fear, anger, and sadness when it is not socially appropriate to display those feelings at a specific time. For example, it is good practice to keep personal and professional matters separate. An executive business professional who is recently mourning the death of a loved one will mask emotional displays of sadness in the work environment in order to be able to perform professionally during an important business presentation. ASD adults, however, may have more difficulty separating their emotional displays of sadness while in the work environment. Begeer and colleagues [21] suggest that ToM may be required to appreciate how an emotion-masking display creates a false belief in others. However, it is also possible that individuals with autism require an additional social script to discern between the emotions being displayed versus the emotions being masked. For example, if an individual with autism has learned that the visual cue for the label "happy" is seeing a smile on someone's face, then the ASD individual may generalize that anyone who smiles is "happy," even when a person smiling may also be crying.

\section{INDIVIDUAL EXPERIENCES}

Authors Lawson, Grandin, Willey, Murray, Parker, Purkis, and Williams are all living with ASD and have personally expressed that they are not good at shifting attention, but excel in focusing on one task at a time [6, $7,22-26]$. The stories of individuals living with ASD tell us so much about why they do what they do (http://www.oapublishinglondon.com/).

"It is a lurch for us as individuals with $A S D$ to be precipitated into a new attention tunnel from the one we are engaged in. It makes us feel bad. Therefore, engaging with us on the basis of our own interests makes it much more comfortable for us than bringing other pressing interests to bear" (D.K.C. Murray, personal communication, April 16, 2007).

Being single minded can often lead to a person becoming an expert in his/her field. Many ASD individuals agree with the following statement:

'I believe my autism gives me the added ability to focus in depth and this gives me the edge I need in my work', [6, 14, 25, 26].

Others have stated that they blame their autistic disposition for their: 'failure to make it in a world where being socially minded is the only normal' [27] (http://www.oapublishinglondon.com/).

\section{WHAT WORKS AND PRACTICAL POINTS}

When it comes to scripting a process, (e.g. making a sandwich, washing hands, getting dressed, etc.) parents and caretakers should consider that ASD individuals typically learn the steps in sequential order. If an ASD person is completing a task that includes 5 or more steps and he/she is interrupted at step 3, the ASD individual may need to start the process over again at step 1, as the interruption was not a part of the initial script. This might be an OP issue.

\section{CONVERSATIONAL CONCEPTS IN ASD}

The following examples are more connected to how individuals on the autism spectrum process information, than they are directly to issues of ToM. Many ASD individuals are more comfortable speaking in terms of direct communication, such as, "No, I do not want the cookie," opposed to communication that includes similes or metaphors, such as "I need a cookie as much as superman needs kryptonite." Direct communication, or "straight talk" might be a bit "black and white"' and literal but it represents the way ASD individuals understand and experience things.

When it comes to "body language" individuals with ASD hear you better when your body is quiet. Many individuals with ASD can easily become side tracked by the speaker's animation.

Writing social scripts and role playing is a great way to practice different types of social exchanges. Additionally, checking in with family and friends to ask them if they were joking, teasing, being sarcastic or if they meant the words they said, just the way they sounded is another helpful way to learn social cues. "My family know I have difficulties figuring these things out so they are happy to accommodate me." (W.B. Lawson, personal communication, October 3, 2016).

\section{CONCLUSION AND IDEAS FOR FURTHER DISCUSSION}

Repetitive, single focused interests and behaviour in ASD have more to do with how attention is processed and less to do with lacking in 'theory of mind' [20]. Poor OP has a big role to play in many of the situations previously outlined. Some may argue that not being able to put oneself into someone else's shoes (metaphorically) denotes selfishness and egocentricity. Indeed, the term "autism" suggests "self" but, what if 
this was because attention is grouped in one place at any one time, rather than divided between "self" and "other" [28], thus missing the bigger picture? What if this difficulty has more to do with issues in shifting attention and what if we could mediate this through building connections via interest? If the research shows that ASD individuals display a difference in their ability to attend [29], then we should be exploring ways to assist ASD individuals to enhance their attention; this is another factor that dictates to the patterns, characteristics, and behaviours seen in ASD, that are often not understood in the NT population.

\section{REFERENCES}

[1] Premack D, Woodruff G. Does the chimpanzee have a theory of mind? Behavioral and Brain Sciences 1978 1; 1(04): 515-26.

[2] Baron-Cohen S. Mindblindness: An essay on autism and theory of mind. MIT press 1997.

[3] Baron-Cohen S. The empathizing system. Origins of the social mind: Evolutionary Psychology and Child Development 2005; 468-92.

[4] Baron-Cohen S, Leslie AM, Frith U. Does the autistic child have a "theory of mind"? Cognition 1985; 21(1): 37-46. https://doi.org/10.1016/0010-0277(85)90022-8

[5] Leslie AM. Pretense and representation: The origins of" theory of mind." Psychological Review 1987; 94(4): 412. https://doi.org/10.1037/0033-295X.94.4.412

[6] Lawson WB, Dombroski BA. Might we be Calling Problems Seen in Autism Spectrum Conditions: 'Poor Theory of Mind,' when actually they are related to non-Generalised 'Object Permanence'? Journal of Intellectual Disability-Diagnosis and Treatment 2015; 3(1): 43-8.

https://doi.org/10.6000/2292-2598.2015.03.01.6

[7] Grandin T. Thinking in pictures: My life with autism (expanded edition). Vintage Anchor Publishing 2006.

[8] Lawson W. Life behind glass. New South Wales, Australia: Southern Cross University Press 1998.

[9] Belmonte MK, Allen G, Beckel-Mitchener A, Boulanger LM, Carper RA, Webb SJ. Autism and abnormal development of brain connectivity. The Journal of Neuroscience 2004; 24(42): 9228-31. https://doi.org/10.1523/JNEUROSCI.3340-04.2004

[10] Belmonte MK, Cook EH, Anderson GM, Rubenstein JL, Greenough WT, Beckel-Mitchener A, Courchesne E, Boulanger LM, Powell SB, Levitt PR, Perry EK. Autism as a disorder of neural information processing: directions for research and targets for therapy. Molecular Psychiatry 2004; 9(7): 646-63.

https://doi.org/10.1038/sj.mp.4001499

[11] Bertone A, Mottron L, Jelenic P, Faubert J. Enhanced and diminished visuo-spatial information processing in autism depends on stimulus complexity. Brain 2005; 128(10): 2430-41. https://doi.org/10.1093/brain/awh561
[12] Lawson, W. Autism taking over, (Published thesis) Germany: Lambert 2011.

[13] Murray DKC. Attention tunneling and autism. Shattock $P$, Linfoot G, Eds. Living with autism: the individual, the family and the professional, Autism Research Unit, University of Sunderland, Sunderland 1992; pp. 89-97.

[14] Lawson $W$. The passionate mind: how individuals with autism learn 2011.

[15] Happé F, Frith U. The weak coherence account: detailfocused cognitive style in autism spectrum disorders. Journal of Autism and Developmental Disorders 2006; 36(1): 5-25. https://doi.org/10.1007/s10803-005-0039-0

[16] Brandwein AB, Foxe JJ, Butler JS, Russo NN, Altschuler TS Gomes H, Molholm S. The development of multisensory integration in high-functioning autism: high-density electrical mapping and psychophysical measures reveal impairments in the processing of audiovisual inputs. Cerebral Cortex 2012; bhs 109 .

[17] Miller LJ, Schoen SA, Brett-Green B, Reale M, Coll J. Quantitative psychophysiologic evaluation of sensory processing in children with autism spectrum disorders. A final report for cure autism now. Manuscript in Preparation 2005.

[18] Goldstein G, Johnson CR, Minshew NJ. Attentional processes in autism. Journal of Autism and Developmental Disorders 2001; 31(4): 433-40.

https://doi.org/10.1023/A:1010620820786

[19] Lawson W. Sensory connection, interest/attention and gamma synchrony in autism or autism, brain connections and preoccupation. Medical Hypotheses 2013; 80(3): 284-8. https://doi.org/10.1016/j.mehy.2012.12.005

[20] Begeer S, Banerjee R, Rieffe C, Terwogt MM, Potharst E, Stegge $\mathrm{H}$, Koot HM. The understanding and self-reported use of emotional display rules in children with autism spectrum disorders. Cognition \& Emotion 2011; 25(5): 94756. https://doi.org/10.1080/02699931.2010.516924

[21] Willey LH. Pretending to be Normal: Living with Asperger's Syndrome (Autism Spectrum Disorder) Expanded Edition. Jessica Kingsley Publishers 2014.

[22] Murray D, Lesser M, Lawson W. Attention, monotropism and the diagnostic criteria for autism. Autism 2005; 9(2): 139-56. https://doi.org/10.1177/1362361305051398

[23] Parker E. Inside the Autism Experience 2012. http://www.eileenparker.com/eileen-parker-4/

[24] Purkis J, Williams D. Finding a different kind of normal: Misadventures with Asperger syndrome. Jessica Kingsley Publishers 2006.

[25] Williams D. Nobody nowhere. Doubleday 1992.

[26] Blackburn R. personal story, Autism Master's Course, distance education students: Residential weekend talk, University of Birmingham, UK 2011.

[27] Gomot M, Belmonte MK, Bullmore ET, Bernard FA, BaronCohen S. Brain hyper-reactivity to auditory novel targets in children with high-functioning autism. Brain 2008; 131(9): 2479-88.

[28] American Psychiatric Association. DSM 5. American Psychiatric Association 2013. https://doi.org/10.1093/brain/awn172

\section{DOI: https://doi.org/10.6000/2292-2598.2017.05.01.1}

(c) 2017 Lawson and Dombroski; Licensee Lifescience Global.

This is an open access article licensed under the terms of the Creative Commons Attribution Non-Commercial License (http://creativecommons.org/licenses/by-nc/3.0/) which permits unrestricted, non-commercial use, distribution and reproduction in any medium, provided the work is properly cited. 